\title{
What Psychotherapy Do Centenarians Need?
}

\author{
Geon Ho Bahn \\ Department of Psychiatry, Kyung Hee University School of Medicine, Seoul, Korea
}

The life expectancy of human beings exceeds 80 years in Korea. Due to the low birth-rate, the proportion of aged individuals, including centenarians (aged 100 years and above), is increasing rapidly. While the life span increases, the available socioeconomic and psychological support system for the elderly is not adequate. Developmental milestones for such aged individuals have yet to be established. The most formidable physical challenge of the elderly is cognitive deficit, such as dementia, due to deterioration of the brain. The elderly suffer from psychological ailments, especially depression and suicide. On the other hand, although centenarians comprise a very old age group, they live long without suffering from illness. Even a few late nonagenarians are healthier than early nonagenarians. Although physical and mental symptoms can be handled with medications, we need additional interventions to enhance mental health, such as psychotherapy and lessons from centenarians. Performance in developmental tasks during psychotherapy is an important criterion for mental health assessment. Therefore, the authors reviewed emotional, behavioral, and lifestyle patterns of centenarians to design appropriate developmental tasks. Common health tips for centenarians include "stay active, interact with relatives, and follow a balanced diet." The major difference in psychotherapy between the elderly and the younger population is the multigenerational transference. The most difficult concern in the psychotherapy of the elderly, compared with younger individuals, is coping with death. Sex imbalance-more women than men-is a unique phenomenon that should be addressed in psychotherapy.

Psychoanalysis 2018;29(2):27-32

KEY WORDS: Centenarian · Development $\cdot$ Mental health · Psychotherapy $\cdot$ Separation-individuation · Multigeneration.

Received: February 23, 2018 Revised: March 21, 2018 Accepted: March 23, 2018

Address for correspondence: Geon Ho Bahn, MD

Department of Psychiatry, Kyung Hee University School of Medicine, 26 Kyungheedae-ro, Dongdaemun-gu, Seoul 02447, Korea

Tel: +82-2-958-8556, Fax: +82-2-957-1997, E-mail: mompeian@khu.ac.kr

\section{Introduction}

The individuals who were 65 years old or more are called “elderly" (Statistics Korea 2017). In 2017, the elderly comprised $13.8 \%$ of the total population, and it is expected to reach $47.7 \%$ by 2045 (Statistics Korea 2017). In Japan, the percentage of the elderly population was $25 \%$ in 2013 , and is expected to exceed $30 \%$ in 2025 , and reach almost $40 \%$ in 2060 (Arai et al. 2015). As the life expectancy becomes longer, the older population is itself ageing (United Nations 2013). Older persons aged 80 years or over (the "oldest old") will be 392 million by 2050 . Among them, the number of centenarians (aged 100 and above), show the greatest increase, from approximately 441,000 in 2013 to 3.4 million in 2050 and 20.1 million in 2100 .

Centenarians are celebrities of aging, our living links to history, and our role models for the future of aging (Franklin

This is an Open Access article distributed under the terms of the Creative Commons Attribution Non-Commercial License (http://creativecommons.org/licenses/by-nc/4.0) which permits unrestricted non-commercial use, distribution, and reproduction in any medium, provided the original work is properly cited. and Adler 2013). Interestingly, "centenarians" refers to people who live not only for over hundred years, but also are in good health, rather than referring to those living with illnesses (Mobley 2016).

Consultation-liaison psychiatry service for the elderly seems to be more frequent now than in the past, with the increase in their proportion, but it is relatively less common in clinical practice than for other age groups (Ryu and Kwon 2008). This is because the observed functional decline and loss of energy in these individuals were misinterpreted normal stages of aging. Especially, as age increases, even though it is necessary to apply physical and emotional development tasks and criteria appropriate for specific age groups, the judgment is based on adulthood in general. Colarusso (1992) proposed the developmental milestones for late adulthood and late late adulthood. Centenarians' developmental challenges may differ from those of late adulthood, so the tactics and strategies of psychotherapy should be different from the general geriatric psychotherapy.

To establish the developmental tasks and identify the skills suitable for psychotherapy of centenarians, the knowledge and experience of their normal psychology should be prioritized. In this review, we examine the psychological characteristics of 
the elderly, focused on the rapidly increasing proportion of centenarians. Taking inspiration from the secrets behind their healthy body and mind, even in an advanced age, we seek to establish developmental milestones and identify skills suitable for psychotherapy for their age.

\section{Developmental Milestones for Centenarians}

One of the reasons why psychoanalytical theory is precious is that, for the first time, it divides the development of man into stages. Sigmund Freud had developed a theory of psychosexual development that includes from infancy to puberty, not to adulthood (Freud 1905a). Erik Erikson's psychosocial theory, which introduced the evolution of adult development, focused mainly on assessing the development of the adolescent identity (Erikson 1963). This is not surprising, given the fact that the average life expectancy of Americans in the 1950s was 65 years for white men and 72 years for white women (Arias 2012). Colarusso (1992) extended the adulthood from young, middle, and late adulthood to late late adulthood. The developmental tasks for late adulthood are: maintaining the body image and physical integrity, preparing for death, accepting the death of spouses and friends, conducting life review, and maintaining sexual interests and activities. In addition, we can expect the emergence of wisdom as the capacity for new forms of thought. Given that the average life expectancy is over 80 years, and the proportion of centenarians is increasing, a developmental theory that can be applied to them is needed.

\section{Physical Disabilities in Older Ages}

Before discussing developmental tasks in the elderly, we must consider the physical functioning that is also the major determinants of the life span (Canada et al. 2016). At the age of 100 , there may be difference in health, based on sex. From the large electronic health records in United Kingdom between 1990 and 2013, 11,084 centenarians (8,982 women and 2,102 men), fewer men than women become centenarians, but women centenarians had a higher rate of geriatric syndromes, such as falls, fractures, hearing and vision impairment, and dementia, than men (Hazra et al. 2015). These findings are consistent with the fourth stage of the epidemiologic transition, "the age of delayed degenerative diseases" (Hazra and Gulliford 2017).

Recently, the rapid increase in the elderly population has emphasized the importance of consultation for the elderly in psychiatry (Yamada et al. 2012). The flow of geriatric psychiatry related to diseases can be divided into two major cat- egories. From the biological perspective, the aged individuals have cognitive disorders, such as delirium and dementia, which result from brain abnormalities (Gutzmann and Qazi 2015). In fact, the greatest fear of "oldest old" is significant cognitive impairment and dementia (Boeve et al. 2003). Fear of the prospect of dementia is greater than the fear of death. In psychiatric practice, old age is associated with disorders often connected to the process of aging, such as depression, anxiety, and substance-related disorders (Gutzmann and Qazi 2015). As the studies on elderly individuals have progressed, three issues have raised concern among clinicians: the problem faced by elderly members of racial and ethnic minority groups, the inadequacies of long-term care (especially outside the family), the need for a health-maintenance approach toward medical care of aging individuals (Gallagher-Thompson et al. 2000).

\section{Higher Rate of Suicide in Older Individuals}

Psychiatric counseling and psychoanalytic approach for the elderly is different from that for other age groups because of chronic and complicated physical illnesses. When people grow older, they become ill, lose close friends and relatives, lose control over their lives, and lose their status in the society (Colarusso 1992). Older people experience hopelessness, loneliness, depression, or inevitability, and then, consider attempting suicide (Vannoy et al. 2007). By the Durkheim's sociocultural view of suicide, the more thoroughly a person belongs, the lower the risk of suicide (Fernquist 2007). The poorer relationships of old individuals increase the risk of suicide. It is a kind of anomic suicide.

On the comparison of the suicide attempters between elderly and non-elderly adults, elderly attempters revealed the tendency to choose more dangerous methods, such as hanging and poisoning, showed higher lethality, and had lesser history of premorbid psychiatric comorbidities than non-elderly adults (Shin et al. 2015). The fact that suicide is still the number one cause of death of elderly individuals in Korea reflects the problems faced by the elderly in our society (Jang et al. 2014).

\section{The Incredible Secrets of Centenarian's Body}

By studying the life of centenarians, we may find a model for healthy elderly individuals, and develop the developmental tasks suitable for centenarians. There is a case study in physiology on a centenarian cyclist, Robert Marchand (RM) (Billat et al. 2017); RM was born on 26 November 1911, and is 
an amateur cyclist since 1978. It is known that elderly people cannot expect to gradually improve their physical function and improve through training. However, RM's experiment has proved that maximal oxygen consumption and performance could still be increased with training at a very old age. From 101 to 103 years, two years of new polarized training for the centenarian cyclist resulted in improved maximal oxygen consumption, maximal power output, and maximal pedaling frequency. In practice, $\mathrm{RM}$ reset a world record for 1-h track cycling from $24.250 \mathrm{~km}$ to $26.927 \mathrm{~km}$.

\section{Life History of Centenarians}

We can get the entire verbatim life history of centenarians to understand them in depth. The author of the book "If I live to be 100," Neenah Ellis, got a grant from the Corporation for Public Broadcasting to make a radio series, "A History of The 20th Century," with interviews of centenarians, in 1997 (Ellis 2004). The conversations between Ms. Ellis and the centenarians became the basis for a radio series on National Public Radio's Morning Edition in 2000, called “One Hundred Years of Stories." One of the common features among centenarians is a good sense of humor. Anna Wilmot, one of centenarians, said to Ms. Ellis, "I want neighbors to throw my ashes in the pond, so I'm warning them: 'Don't eat the fish, they might be eatin' me!"' Not all, but most centenarians are religious and active in life. Roy Larkin Stamper, born in 1896, has been preaching for about 70 years. Abraham Goldstein has been teaching for 70 years at Baruch College, which was founded in 1919. Although Professor Goldstein is a retired teacher, he still tutors students at Baruch's Zicklin School of Business, New York. Harry Shapiro, still working as a painter, answered the question "What prolongs life?" by saying, "Art and Music. Beyond that, it is to have a heart full of love." Although centenarians do not know all the neighbors, it is interesting that all the neighbors of centenarians recognize them because "they live more than a hundred years" (Ellis 2004).

The longest living people are not rich in the material sense. Cathryn Dwinnell, 107 years old, offers a simple definition of "rich": "Being loved, having friends. I have everything I need." (Franklin and Adler 2013)

\section{Learning from "Blue Zones"}

One of the representative materials on centenarians is "Blue Zones" (Buettner 2008). National Geographic has found five Blue Zones around the world, covering the world's longevity villages. Blue Zones are the regions where the proportion of healthy 90 - or 100-year-old individuals in the total population is unusually high (Buettner 2008). The global Blue Zones are
Sardina in Italy, Ikaria in Greece, Okinawa in Japan, Hojancha in Costa Rica, and Loma Linda, California in USA. Studies on centenarians living in Blue Zones have documented details of their daily life (Buettner 2008). The first lesson to be learned from their lives is to move naturally and be spontaneously active. To do that, people have fun, walk, date, plant a garden, or enroll in a yoga class. Lesson two is "hara hachi bu (腹八分目/はらはちぶんめ),” from the centenarians in Okinawa, meaning “eat until you are 80 percent full.” Lesson three is to avoid meat and processed foods: eat 4-6 vegetables servings daily, limit the intake of meat and preserved fruits and vegetables, lead with beans, eat nuts every day, and stock up. Lesson four is "grapes of life." Centenarians drink wine in Italy and Greece, and sake in Okinawa, in moderation. Lesson five is to see the big picture: craft a personal mission statement, find a partner, and learn something new. Lesson six is to relieve stress. Reduce the noise, wake up early, and meditate. Lesson seven is "belonging." Be more involved and participate in the spiritual community. As seen in Durkheim's sociocultural view of suicide, relationship is very important to stay healthy (Fernquist 2007). Lesson eight is to make family a priority: get closer, establish rituals, create a family shrine, and put family first. The last lesson is about being in the right tribe. To be a centenarian, we need to be surrounded by those who share Blue Zone values.

While the details of each centenarian day-to-day life differed depending on where they grew up, they all seemed to have one thing in common: "stay active" (Mobley 2016). The centenarian psychoanalyst, Hadda Bolgar, answered "Have a richer life and a variety of relationships." when she had a question "What analysts could do to develop themselves in the 21st century?" (Diamond and Christian 2011). A good combination of genes, lifestyle, attitude, wisdom, and innovations is needed to live a long and healthy life (Franklin and Adler 2013).

\section{The Importance of a Partner and Sexuality}

Among the lessons from Blue Zones, we can find the importance of a partner (Buettner 2008). The greatest barrier to being sexually active in old age is the lack of a partner, which particularly affects women (Freak-Poli et al. 2017). In fact, little is known about the sexuality of old individuals, especially nonagenarians and centenarians, despite the steep increase in the aging population (Lindau et al. 2007). Rather, the negative attitude toward sexual expression among the elderly is particularly obvious in nursing homes and long-term care facilities, where rules prohibit, or staff members frown upon, sexual activity among the residents (DeLamater and Friedrich 2002). 
This attitude may be a more important reason why many elderly individuals are not sexually active than the biological changes they experience.

It is not true that old individuals are not interested in sexual pleasure. In the Spanish National Sexual Health Survey of individuals over 65 years old, $62.3 \%$ men and $37.4 \%$ women were found to be sexually active (Palacios-Ceña et al. 2012). The most common sexual activity was touching and caressing without sexual intercourse, followed by masturbation, followed by sexual intercourse for both men and women aged 82-102 (Bretschneider and McCoy 1988). From the nationally representative probabilistic sample of the United States, the frequency of masturbation was reported to differ according to age and sex (Herbenick et al. 2010). Above 70 years of age, no masturbation in the past year was reported $68.6 \%$ women and $53.6 \%$ men, and a few times per month to weekly, was reported in $4.8 \%$ women and $14.0 \%$ men. Although many older adults, especially men, are sexually active, and sexual problems are frequent among old individuals, these issues are discussed less with their therapists than other issues (Lindau et al. 2007)

\section{Developmental Milestones: Being Healthy for Centenarians}

The developmental tasks for aged individuals are quite different from those meant for the previous stages (Colarusso 1992). Beyond maintaining physical integrity and sexual activities, the unique difference is death: preparing for death, and accepting the death of spouses and friends. From a psychoanalytic treatment with a centenarian patient, Settlage (1996) reported four development tasks such as acceptance of necessary dependency, revision of values, acquisition of wisdom, and acceptance of mortality. Acceptance of death of oneself and close individuals might be a new type of separation-individuation (SI) compared with the primary SI between infants and mothers (Mahler 1974), secondary SI of independent adolescents from parents (Blos 1966; Moon and Bahn 2016), and tertiary SI of the elderly due to retirement, letting go of kids, or "intimacy at a distance" (Colarusso 1992). Life review is a worthwhile intervention for reducing depression and hopelessness, and improving quality of life, well-being and specific memory in older adults and also might be one of developmental tasks (Lan et al. 2017).

From the Swedish centenarian study following 100 centenarians from the age of 100 to death of the entire cohort, individuals with better baseline physical reserve appear to have better chances of survival (Hagberg and Samuelsson 2008). Hereditary factors, social relationships, marital status, and personality did not contribute to survival prediction in this ex- ceptional age group. From a theoretical point of view, these data suggest that, in very old age, stochastic determinants may dominate over programmed factors (e.g., family longevity) in determining survival. In a Japanese study comparing the personality characteristics of 1,812 elderly individuals aged 60-84 years, and 70 centenarians with unimpaired cognition aged 100-106 years, high scores in specific personality traits, such as conscientiousness, extraversion, and openness, were associated with longevity (Masui et al. 2006).

In the psychosocial stages of childhood, the development is constituted the proper sequence as identity, intimacy, generativity and ego integrity (Erikson 1963). Based on Harvard's study of adult development (Vaillant 2012), two more tasks has added: "career consolidation" prior to generativity and "keeper of the meaning" prior to integrity. The age at which any task is mastered differs across individuals. From the Harvard's study, warm childhood environment or parental social class could not be considered a predictor of mental health for aged individuals (Vaillant et al. 2014). Psychotropics can alleviate mental disorders, but do not improve brain function. Rather, cognitive, behavioral, and psychodynamic education can enhance mental health. From a study of defensive maturity, men who experienced warm childhoods used more adaptive (mature) defenses than men with less warm childhoods, till midlife (Martin-Joy et al. 2017). However, the difference in defensive maturity disappears by late life, as men who experienced less childhood warmth increase adaptive defenses during the period from mid to late life. This may indicate that developmental processes are underway even in old age.

\section{Psychotherapies in Centenarians}

In medicine, children are treated by pediatricians, and adults are examined by specialists in internal medicine, surgery, ophthalmology, gynecology etc. What about the emotional issues of nonagenarians and centenarians? People have wondered whether the existing models of psychotherapy fit new groups of older people, such as centenarians (Laidlaw 2013) since most of the studies on psychotherapy of older individuals are based on the younger age group (under 80 years).

The word 'centenarian' is not so familiar in the field of psychoanalysis, although it had appeared in one of old articles describing the new computing machine as cybernetics: "To live forever would be infinitely improbable; there would be an outside chance of having an unusually large number of breaks and becoming a centenarian" (Wisdom 1949). Actually, it is not related with analysis or psychotherapy.

A person who is aged 95 will most likely have different needs than one who is 65 . Settlage (1996) presented her poet patient; the first treatment at the age of 94; the second treat- 
ment beginning at the age of 99 . The problems for the first treatment were a severe dizziness and fear of falling which began about three weeks after her husband's death. The patient's presenting problem at the time of the second consultation was severe, pounding palpitations. The symptoms were associated with the preoccupation with death. As a result, psychotherapists working with older people will have to become more knowledgeable about lifespan developmental psychology (Laidlaw and Baikie 2007). Likewise, therapists who will make the most successful transition to the increased age range of their clients are those who view age as just a chronological indicator and nothing more, but are also knowledgeable enough to differentiate normal from pathological aging (Laidlaw and Baikie 2007).

Multigenerational transference might happen between clients in late late adulthood and the psychotherapist (Colarusso 1992). Son or daughter transference is extremely common for elderly clients. The therapist is cast as the client's child, grandchild, or son- or daughter-in-law. A pervasive sense of loneliness and an intensified need for attachment is characteristic of the aging patient, who had lost a primary attachment partner, and who were left very much alone (Valenstein 2000). Erotic transferences in the elderly are frequent, and extremely useful to the therapist who can accept them and manage his or her countertransference responses (Colarusso 1992). For young or middle-aged therapists, painful issues like cancer, the loss of spouses and life-long friends, and the nearness of death, are difficult to handle on a daily basis, even though it is a therapy session. Another harsh countertransference response is because of the elder client's sexuality (Colarusso 1992). If the therapist has not had much experience in working with aged individuals, he/she will not be suited to confront the aged client's vivid sexual fantasies, masturbation, and intercourse. In these respects the age and gender of the older patient vis-à-vis the age and gender of the analyst are significant for the qualitative form of the transference-countertransference and for the course of the analysis.

In psychotherapy of centenarians, the unique concern is the sex imbalance. For all ages 90 and above, there are more women than men, reflecting women's higher life expectancy, and this is increasingly so at higher ages (Laidlaw and Baikie 2007). Most centenarians are women, with 5 female centenarians for every male centenarian in United Kingdom, 2016 (Office for National Statistics 2017). The statistics of the Korean population show that the life expectancy of 65 -year-old men is 18.2 years, and that of women is 22.4 years (Statistics Korea 2017). Although the age-related changes in individuals aged 90 and above are faster for men than for women, the sex imbalance is unlikely to narrow much. Due to this sex imbalance, most therapists cater to older women than older men, and older men may have different needs than those of women. Thus, information about sex is important to contextualize the aging experience in aged individuals (Laidlaw and Baikie 2007).

In spite of Freud's statements about the inapplicability of psychoanalysis to people who are very advanced in years (Freud 1905b), there are nonagenarians and centenarians who want psychoanalytic treatment nowadays. Also, we have nonagenarian and centenarian psychoanalysts. In addition to the late Leo Rangell, who passed away at the age of 97 after 60 years of psychoanalytic writing and practicing, Hedda Bolgar (1909-2013) was an active analyst who saw patients four days a week at age 102 (Shulman 2016).

\section{Conclusions}

The human life span is increasing, and the proportion of centenarians in the total population is increasing. Therefore, the goal of life needs to be changed from "longevity" to "healthy longevity." The developmental tasks performed in childhood, adolescence, and adulthood may be less meaningful for centenarians, but they are still important. In addition, "healthy longevity" needs efforts to establish and perform the developmental tasks critical during this time.

Achieving a fourth SI and maintaining a stable active lifestyle are the important developmental challenges. Efforts to maintain and expand social relationships are also important. To treat centenarians, psychotherapists must learn and experience the centenarians' mind.

\section{Acknowledgments}

The theme of this article was presented at the CME for psychiatric residents of the Korean Association of Psychoanalysis on 4th November, 2017, Seoul, Korea.

\section{Conflicts of Interest}

The author has no financial conflicts of interest.

\section{REFERENCES}

Arias E. United States Life Tables, 2008. National Vital Statistics Reports 2012;61:52-55. [cited 2012 Sep 24]. Available from: https://www. cdc.gov/nchs/data/nvsr/nvsr61/nvsr61_03.pdf.

Arai H, Ouchi Y, Toba K, Endo T, Shimokado K, Tsubota K, et al. Japan as the front-runner of super-aged societies: perspectives from medicine and medical care in Japan. Geriatr Gerontol Int 2015;15:673-687.

Billat V, Dhonneur G, Mille-Hamard L, Le Moyec L, Momken I, Launay T, et al. Case Studies in Physiology: maximal oxygen consumption and performance in a centenarian cyclist. J Appl Physiol (1985) 2017;122:430-434.

Blos P. On adolescence: a psychoanalytic interpretation. New York, NY: Free Press;1966. p.227.

Boeve B, McCormick J, Smith G, Ferman T, Rummans T, Carpenter T, et al. Mild cognitive impairment in the oldest old. Neurology 2003;60:477-480.

Bretschneider JG, McCoy NL. Sexual interest and behavior in healthy 
80- to 102-year-olds. Arch Sex Behav 1988;17:109-129.

Buettner D. The blue zones: lessons for living logner from the people who've lived the longest. 2nd ed. Washington DC: National Geographic Society;2008.

Canada B, Stephan Y, Jaconelli A, Duberstein PR. The moderating effect of chronological age on the relation between neuroticism and physical functioning: cross-sectional evidence from two French samples. J Gerontol B Psychol Sci Soc Sci 2016;71:35-40.

Colarusso CA. Child and adult development: a psychoanalytic introduction for clinicians. 1st paperback ed. New York, NY: Plenum press; 1992.

DeLamater J, Friedrich WN. Human sexual development. J Sex Res 2002;39:10-14

Diamond MJ, Christian C. The second century of psychoanalysis: evolving perspectives on therapeutic action, 1st ed. London: Karnac Books; 2011.

Ellis N. If I live to be 100: lessons from the centenarians. 1st paperback ed. New York, NY: Three Rivers Press;2004.

Erikson E. Childhood and society. New York, NY: W.W. Norton \& Company, Inc.;1963.

Fernquist RM. How do Durkheimian variables impact variation in national suicide rates when proxies for depression and alcoholism are controlled? Arch Suicide Res 2007;11:361-374.

Franklin S, Adler LP. Celebrate 100: centenarians secrects to success in business and life. Hoboken, NJ: Wiley;2013.

Freak-Poli R, Kirkman M, De Castro Lima G, Direk N, Franco OH, Tiemeier H. Sexual activity and physical tenderness in older adults: cross-sectional prevalence and associated characteristics. J Sex Med 2017;14:918-927.

Freud S. Three essays on the theory of sexuality. SE 7. London: Hogarth Press;1905a. p.123-230.

Freud S. On psychotherapy. SE 7. London: Hogarth Press;1905b. p.255268.

Gallagher-Thompson D, Lovett S, Rose J, McKibbin C, Coon D, Futterman A, et al. Impact of psychoeducational interventions on distressed family caregivers. J Clin Geropsychol 2000;6:91-110.

Gutzmann H, Qazi A. Depression associated with dementia. Z Gerontol Geriatr 2015;48:305-311.

Hagberg B, Samuelsson G. Survival after 100 years of age: a multivariate model of exceptional survival in Swedish centenarians. J Gerontol A Biol Sci Med Sci 2008;63:1219-1226.

Hazra NC, Dregan A, Jackson S, Gulliford MC. Differences in health at age 100 according to sex: population-based cohort study of centenarians using electronic health records. J Am Geriatr Soc 2015;63:13311337.

Hazra NC, Gulliford M. Evolution of the "fourth stage" of epidemiologic transition in people aged 80 years and over: population-based cohort study using electronic health records. Popul Health Metr 2017; 15:18.

Herbenick D, Reece M, Schick V, Sanders SA, Dodge B, Fortenberry JD. Sexual behavior in the United States: results from a national probability sample of men and women ages 14-94. J Sex Med 2010;7 Suppl 5:255-265.

Jang SY, Choi B, Ju EY, Kim YM, Kang SB, Park S, et al. Association between restriction of activity related to chronic diseases and suicidal ideation in older adults in Korea. Geriatr Gerontol Int 2014;14:983988.

Laidlaw K. A deficit in psychotherapeutic care for older people with depression and anxiety. Gerontology 2013;59:549-556.

Laidlaw K, Baikie E. Psychotherapy and demographic change: why psychotherapists working with older adults need to be aware of changing demographics now. Nordic Psychology 2007;59:45-58.

Lan X, Xiao H, Chen Y. Effects of life review interventions on psycho- social outcomes among older adults: a systematic review and metaanalysis. Geriatr Gerontol Int 2017;17:1344-1357.

Lindau ST, Schumm LP, Laumann EO, Levinson W, O'Muircheartaigh CA, Waite LJ. A study of sexuality and health among older adults in the United States. N Engl J Med 2007;357:762-774.

Mahler MS. Symbiosis and individuation. The psychological birth of the human infant. Psychoanal Study Child 1974;29:89-106.

Martin-Joy JS, Malone JC, Cui XJ, Johansen PØ, Hill KP, Rahman MO, et al. Development of adaptive coping from mid to late life: a 70-year longitudinal study of defense maturity and its psychosocial correlates. J Nerv Ment Dis 2017;205:685-691.

Masui Y, Gondo Y, Inagaki H, Hirose N. Do personality characteristics predict longevity? Findings from the Tokyo Centenarian Study. Age (Dordr) 2006;28:353-361.

Mobley P. If I live to be 100: the wisdom of centenarians. New York, NY: Welcome Books;2016.

Moon DS, Bahn GH. The concept of synchronization in the process of separation-individuation between a parent and an adolescent. Psychoanalysis 2016;27:35-41

Office for National Statistics. Statistical bulletin: estimates of the very old (including centenarians): 2002 to 2016 [updated 2017 Sep 27; cited 2018 April 10]. Available from: https://www.ons.gov.uk/peoplepopulationandcommunity/birthsdeathsandmarriages/ageing/bulletins/ estimatesoftheveryoldincludingcentenarians/2002to2016.

Palacios-Ceña D, Carrasco-Garrido P, Hernández-Barrera V, AlonsoBlanco C, Jiménez-García R, Fernández-de-las-Peñas C. Sexual behaviors among older adults in Spain: results from a populationbased national sexual health survey. J Sex Med 2012;9:121-129.

Ryu SG, Kwon HJ. Psychosomatic management of medically ill elderlyfocused on consultation psychiatry. Korean J Psychosom Med 2008; 16:25-30.

Settlage CF. Transcending old age: creativity, development and psychoanalysis in the life of a centenarian. Int J Psychoanal 1996;77(Pt 3):549-564.

Shin HW, Lee KJ, Kim H. The clinical characteristics of elderly suicide attempters visiting emergency room. Korean J Psychosom Med 2015; 23:100-106.

Shulman M. "Unavoidable satisfactions": the analyst's pleasure. J Am Psychoanal Assoc 2016;64:697-727.

Statistics Korea. Statistics of old ages, 2017. [updated 2017 Sep 26; cited $2018 \mathrm{Mar} 20]$. Available from: http://kostat.go.kr/portal/korea/ kor_nw/2/6/5/index.board?bmode $=$ read\&aSeq $=363362 \&$ pageNo $=$ \&rowNum $=10 \&$ amSeq $=\&$ sTarget $=\& s T x t=$.

United Nations. World population ageing 2013. Available from: http:// www.un.org/en/development/desa/population/publications/pdf/ageing/WorldPopulationAgeing2013.pdf.

Vaillant GE. Positive mental health: is there a cross-cultural definition? World Psychiatry 2012;11:93-99.

Vaillant GE, Okereke OI, Mukamal K, Waldinger RJ. Antecedents of intact cognition and dementia at age 90 years: a prospective study. Int J Geriatr Psychiatry 2014;29:1278-1285.

Valenstein AF. The older patient in psychoanalysis. J Am Psychoanal Assoc 2000;48:1563-1589.

Vannoy SD, Duberstein P, Cukrowicz K, Lin E, Fan MY, Unützer J. The relationship between suicide ideation and late-life depression. Am J Geriatr Psychiatry 2007;15:1024-1033.

Wisdom JO. Cybernetics, or control and communication in the animal and the machine. Int J Psychoanal 1949;30:133-137.

Yamada K, Hosoda M, Nakashima S, Furuta K, Awata S. Psychiatric diagnosis in the elderly referred to a consultation-liaison psychiatry service in a general geriatric hospital in Japan. Geriatr Gerontol Int 2012;12:304-309. 